\title{
AN ENERGY EFFICIENCY GUIDE for use in CLEANROOM PROGRAMMING
}

December 2001

Sponsored by the

\section{NORTHWEST ENERGY EFFICIENCY ALLIANCE \& CALIFORNIA ENERGY COMMISSION}

Authors: Bill Tschudi, PE, Principal Investigator Dale Sartor, PE, Principal Investigator Tengfang Xu, Ph.D.

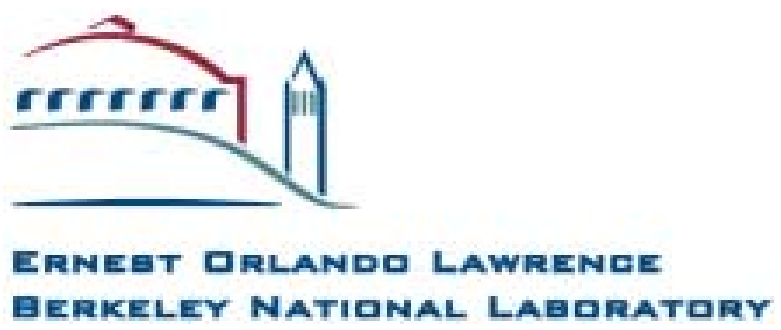




\section{Legal Notice}

The Lawrence Berkeley National Laboratory, 1 Cyclotron Road, Berkeley, CA 94720 is a National Laboratory of the U.S. Department of Energy (DOE) managed by the Regents of the University of California for the U.S. Department of Energy under Contract Number DE-AC03-76SF-000-98. This report was prepared as an account of work co-sponsored by the Northwest Energy Efficiency Alliance (NEEA) and the California Energy Commission (Commission, Energy Commission) and pursuant to an M\&O Contract with the United States Department of Energy (DOE). Neither the Regents of the University of California, nor the DOE nor the California Energy Commission, nor the Northwest Energy Efficiency Alliance, nor any of their employees, contractors, or subcontractors, makes any warranty, express or implied, or assumes any legal liability or responsibility for the accuracy, completeness, or usefulness of any information, apparatus, product, or process disclosed, or represents that its use would not infringe privately owned rights. Reference herein to any specific commercial product, process, or service by trade name, trademark, manufacturer, or otherwise, does not necessarily constitute or imply its endorsement, recommendation, or favoring by The Regents of the University of California, or the DOE, or NEEA, or the California Energy Commission. The views and opinions of the authors expressed herein do not necessarily state or reflect those of The Regents of the University of California, the DOE, the NEEA, or the California Energy Commission, or any of their employees, or the United States Government, or any agency thereof, or the State of California. This report has not been approved or disapproved by the Regents of the University of California, the DOE, the NEEA, or the California Energy Commission, nor has The Regents of the University of California, the DOE, the NEEA, or the California Energy Commission passed upon the accuracy or adequacy of the information in this report. 


\section{Acknowledgements}

Special thanks are extended to industry participants for identifying key areas for consideration and to the sponsors and other contributors to this guide.

\section{California Energy Commission}

Pramod Kulkarni

Anthony Wong, PE

Northwest Energy Efficiency Alliance

Blair Collins

Michael Ponder, PE

Lawrence Berkeley National Laboratory

Steve Greenberg, PE

Anthony Yuen, PE

Facility Planning \& Resources, Inc.

Thomas E. Hansz, AIA

Rumsey Engineers (formerly Supersymmetry)

Peter Rumsey, PE

Jacobs Engineering Group

Greg Owen, PE 


\section{Table of Contents}

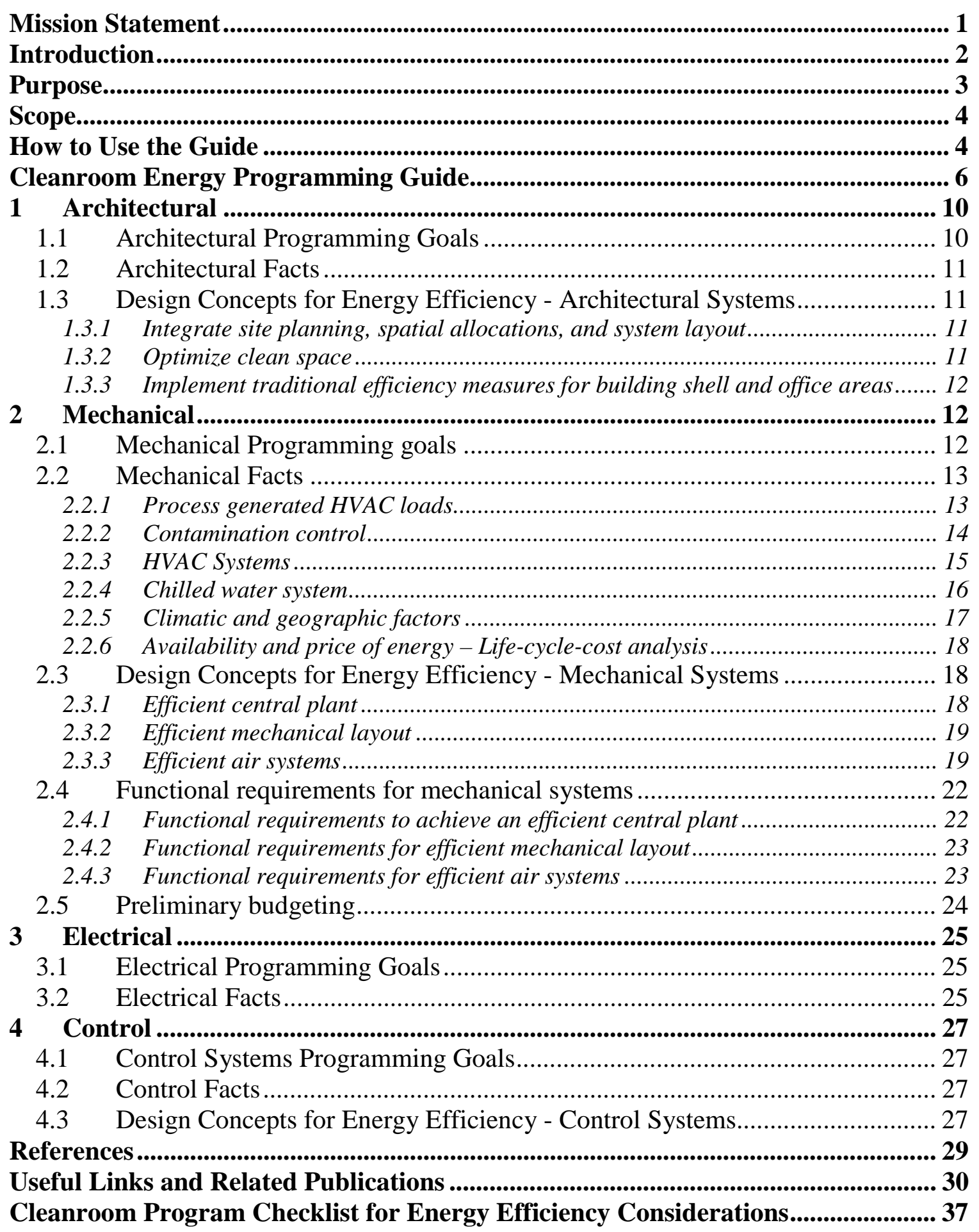




\section{Mission Statement}

The mission of this Cleanroom Energy Programming guide is to 1) elevate the importance of energy efficiency as a program requirement for cleanroom design, and 2) provide guidelines for decisions made early in a cleanroom design project to assist cleanroom owners, and designers to achieve energy efficiency while maintaining or improving other program requirements. The guide provides useful information at the programming phase of a project concerning issues that could have significant impact on energy use. It is intended to stimulate the programming team to make informed decisions to improve overall energy efficiency while addressing other program issues. 


\section{Introduction}

Programming of cleanroom facilities is a complex planning exercise dealing with hundreds of interrelated, and at times, conflicting goals and facts. Traditionally, decisions affecting a number of major design features are made during this phase. These decisions often have adverse energy implications and are made for a variety of reasons such as scheduling pressures due to long lead-times, or availability of material. Or, the owner and design team may have preconceived preferences based on prior experience, company policy, or personal preferences. In many cases decisions are made to satisfy other program goals with little consideration for long-term operational cost - including the cost of energy. In addition, decisions, which lock-in inefficient design, are commonly dictated by first cost considerations without benefit of life cycle, or cost of ownership evaluations.

Most cleanroom design and construction projects are operating under very compressed schedules putting additional pressure on the need for rapid decisions during the programming phase. Previously, there was little publicly available guidance to aid in evaluating the energy implications of certain cleanroom design options selected and locked-in during this phase of the project.

This guide, while recognizing that there is no single, optimal design solution, provides ideas for including energy as an important cleanroom design program requirement. By considering the long-term energy implications of major design decisions, the programming team consisting of designers, owner/operators, and other stakeholders will be able to make informed decisions early in the project to meet their long-term interests, as well as optimize first cost. Typically, as Figure 1 illustrates, cleanroom environmental system energy use represents up to one half of the total in a typical cleanroom.

Since HVAC systems operate continuously, it is important to consider strategies and designs to maximize efficiency in the operation of the facility. This guide provides selected technical bases, and informational links to aid decision-making during the programming phase. In addition, the methodology used to evaluate energy performance will also be useful during later phases of the design. By highlighting the energy related issues at this phase, some owners may choose to defer some of the key decisions pending a more detailed evaluation during design development. The guide is meant to present a framework for the programming team to evaluate energy efficiency with the same robustness as many other design parameters.

By comparing different design options at the programming stage, the programming team will be considering life cycle cost and total cost of ownership rather than strictly first cost. The owner and design team will always have the option of selecting design features that minimize first cost, but they will now also have information highlighting where to make choices with energy efficiency impacts. Reduction of first cost and energy efficiency are not mutually exclusive. Many strategies will result in lower first cost as well as lower on-going energy cost. 


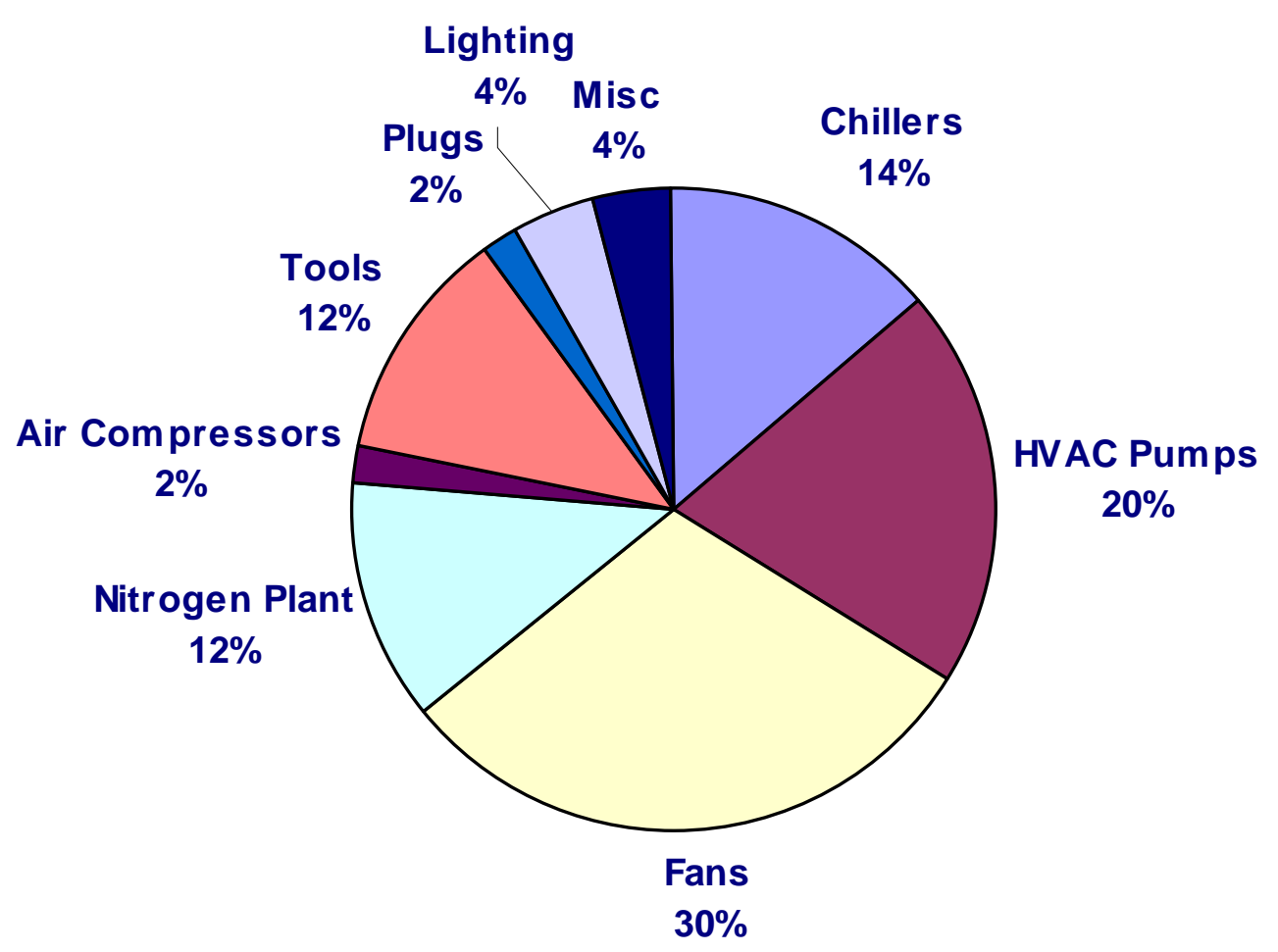

Figure 1. Representative Cleanroom Energy End Use

\section{Purpose}

The purpose of this guide is to provide a resource to help cleanroom owners, operators, and designers establish and implement an energy strategy early in the design process - at the programming phase. Many critical decisions are made during the early phases of design and can later become irreversible due to the progress of the project. Many key program requirements if developed in a routine manner have potentially adverse energy efficiency implications. This guide provides information to stimulate comparison of alternatives and to set direction for issues with large energy impact. A further purpose of the guide is to provide a framework to highlight significant design and operational issues affecting energy use thereby encouraging cleanroom owners to make informed decisions. The guide identifies issues potentially important to energy use, and related key considerations. It is expected that the guide will stimulate a more robust investigation of the issues and related energy implications that need to be addressed during later detailed design phases. Programming methodology that gives equal weight to the efficiency of energy intensive systems and components in addition to other key program requirements can avoid "locking-in" an inefficient design. 


\section{Scope}

This guide is intended to focus on selected energy intensive areas normally addressed in the program for any cleanroom facility regardless of its application or cleanliness type. As a result, it includes topics that may not apply to all situations. For example, raised floors have various energy related issues, but are not a design feature in certain cleanrooms. The guide primarily focuses on cleanroom elements that have importance to energy use in the facility. Therefore, it is recommended that this guide be used along with other traditional planning guidance, design resources, manuals, handbooks, tools, etc. to address other important design issues. Each programming team should consider the advice of this guide where appropriate, and also use other design criteria and costbenefit evaluations, including life cycle or cost of ownership evaluations. This guide is intended primarily for new construction but we anticipate that many concepts can be applied to retrofit situations as well.

This guide focuses on energy use in building systems important to the efficient operation of cleanrooms. Prior benchmarking of energy use in cleanrooms (also see http://ateam.lbl.gov/hightech/Cleanroom/Benchmarking/), and load characterization has highlighted the fact that environmental systems in cleanrooms account for up to $50 \%$ of the total electrical load in cleanroom facilities. Consequently, this guide focuses primarily on design considerations affecting energy efficiency of those systems.

While process loads in cleanrooms usually are very energy intensive, there are so many variations of processes in cleanrooms, that a standard treatment would not be appropriate in this type of guide. Planning decisions for process systems often have significant energy implications and there is difficulty in accurately estimating the loads. While not the focus of this guide, the programming team can use the same type of approaches to determine energy efficiency opportunities in the design of process systems and components.

\section{How to Use the Guide}

Ideally, cleanroom owner/operators will see value in using this guide as part of the planning process employed by the programming team. Its use should be included as a requirement in the owner's Requests For Proposal for the selection of the programming/planning team. Once the programming team is assembled and the program is being defined, the guide should be reviewed to identify the topics of relevance to the project. A checklist of some of the most significant topics is provided which can be used to stimulate discussion amongst the programming participants as the program content is developed. Issues that could have major energy implications are discussed, and links to other available guidance (such as the LBNL Laboratory Design Guide, also see http://eande.lbl.gov/R-LabDG/HELP3.HTM) are provided. The team may decide that some decisions can be deferred pending further evaluation, or they may incorporate the decision into later design phases. To make a determination, a simplified life cycle cost or cost of ownership - analysis may be required.

Since this guide focuses only on issues important to energy use, it is not intended to address all aspects of a cleanroom program. It is recommended that it be used in conjunction with other design guides and traditional practice. This guide references other 
design guidance when appropriate. It is expected that the owner/design team will of course make the final determination of what is best for the project. 


\section{Cleanroom Energy Programming Guide}

Any cleanroom programming process requires close interaction and collaboration among architects, engineers, and various representatives of the owner from the very beginning of design. It is essential to gather inputs from all stakeholders in the project to begin the integration of information, analysis, and decision-making. Because there are often different and sometimes conflicting considerations that could affect the final decisionmaking for certain critical issues, it is important to conduct a structured programming exercise.

It is helpful to organize the information to allow the team to focus on issues that eventually will influence the design of the project. A common method of organizing the body of data to be developed during programming includes the following five categories of information:

Goals:

Statements of cleanroom objectives in terms of function, form, economy, and time. These are Owner's intentions for the cleanroom performance and design.

Facts:

Background information related to the cleanroom process, staffing, materials, and existing building and/or site conditions. Process equipment data and code requirements are facts.

Concepts:

Ideas for improving performance, indicating priorities and characterizing space and systems. Conflicting concepts will be tested during the early design phases.

Needs:

Spreadsheets quantifying area requirements, utility requirements, project budget and critical project schedule milestones. The utility matrix, \& airflow rates are key needs.

Problem Statement:

Statements summarizing design directions and conclusions based upon the four previous groups of information. 
In keeping with this format, this guide provides selected information in these categories for the following disciplines:

- Architectural

- Mechanical,

- Electrical.

- Control

- Other;

Each technical section lists planning and design information for various design issues, such as functional requirements, codes, specific technologies, design concepts, etc. The guide information is primarily focused on the following three categories:

- Goals - description of qualitative goals;

- Facts - description of the basis for concept development and definitions;

- Design concepts - description of technologies/ approaches used to achieve the programming objectives. This may include metrics - generally quantitative data used to set performance goals (if applicable) 
Table 1 Structure of cleanroom energy programming guide

\begin{tabular}{|c|c|c|c|}
\hline & Goals & Facts & Design Concepts \\
\hline General & 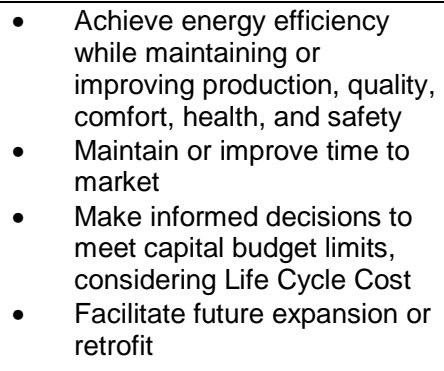 & $\begin{array}{ll}\text { - } & \text { Functional requirements } \\
\text { - } & \text { Construction schedules } \\
\text { - } & \text { Growth Projections } \\
\text { - } & \text { Price of Energy }\end{array}$ & - Life cycle cost evaluation \\
\hline Architectural & $\begin{array}{ll}- & \frac{\text { Achieve efficient layout }}{\text { Optimize clean space }} \\
-\quad & \frac{\text { Use traditional building }}{\text { efficiency measures }}\end{array}$ & $\begin{array}{ll} & \text { Site plan and analysis } \\
\text { - } & \text { Applicable Codes } \\
\text { Cleanliness and space } \\
\text { requirements } \\
\text { - } \quad \text { Consider future growth }\end{array}$ & $\begin{array}{ll}\text { - } & \frac{\text { Integrate site planning }}{\text { and space/system layout }} \\
\text { - } & \text { Plan minimum clean } \\
\text { space } \\
\text { - } \\
\text { Adopt traditional building } \\
\text { efficiency measures }\end{array}$ \\
\hline \begin{tabular}{|l|}
\multicolumn{2}{|c|}{ Mechanical } \\
(HVAC) \\
\end{tabular} & 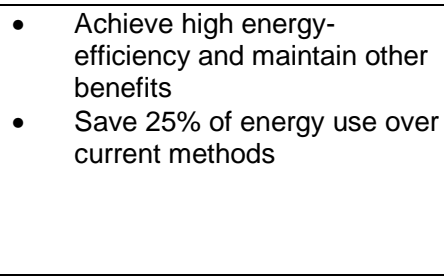 & $\begin{array}{ll} & \text { Process } \\
\text { - } & \frac{\text { Contamination control }}{\text { Thermal environmental system }} \\
\text { - } & \text { Climate/ geographical impact } \\
\text { - } & \frac{\text { Chilled Water system }}{\text { Code and standards }} \\
\text { - } & \text { Requirements } \\
\text { Budget }\end{array}$ & $\begin{array}{ll}\text { - } & \text { Lowest energy use per } \\
\text { - } & \frac{\text { unit of useful work }}{\text { Efficient central plant }} \\
\text { - } & \frac{\text { Efficient mechanical }}{\text { layout }} \\
\text { - } & \text { Efficient air system }\end{array}$ \\
\hline Electrical & $\begin{array}{ll}- & \text { Achieve efficient distribution } \\
\text { - } & \text { Monitor electrical loads }\end{array}$ & $\begin{array}{l}\text { - Process and HVAC electrical } \\
\text { loads }\end{array}$ & $\begin{array}{ll} & \text { Efficient electrical } \\
& \text { equipment }\end{array}$ \\
\hline Control & $\begin{array}{l}\text { - } \quad \text { Achieve effective monitoring } \\
\text { Achieve ability to achieve } \\
\text { efficiency for all load } \\
\text { conditions }\end{array}$ & $\bullet$ & $\begin{array}{ll}\text { - } & \text { Sufficient monitoring } \\
\text { points } \\
\text { - } \quad \text { Interoperable controls }\end{array}$ \\
\hline
\end{tabular}

Table 2 illustrates a common framework utilized in programming cleanroom projects. The framework is applicable both for new "Greenfield" projects and for retrofit projects. A project programming team should understand that "programming" considers activities throughout the life cycle of a project to ensure that critical issues with an impact on energy use are taken into consideration appropriately. 
Table 2 Cleanroom energy programming framework

\begin{tabular}{|c|c|c|c|c|c|}
\hline & Goals & Facts & Concepts & Needs & $\begin{array}{l}\text { Problem } \\
\text { Statement }\end{array}$ \\
\hline $\begin{array}{l}\text { Cleanroom } \\
\text { Functions } \\
\text { Process } \\
\text { People } \\
\text { system }\end{array}$ & $\begin{array}{ll}\text { - } & \text { Achieve energy efficiency } \\
\text { - } & \text { Right-size process \& facility } \\
\text { - Systems } & \text { Achieve thermal efficiency } \\
\text { - } & \text { Thermal integration } \\
\text { - } & \text { Maintain or improve comfort and } \\
\text { - } & \text { Mafety } \\
\quad & \text { Maintain or improve production and } \\
& \text { roduct quality }\end{array}$ & $\begin{array}{ll}\text { - } & \text { Process } \\
\text { - } & \text { Description } \\
\text { - } & \text { Contamination requirements } \\
\text { - } & \text { Accurate load estimate, } \\
& \text { diversification, and safety factors } \\
\text { - } & \text { Exhaust requirements } \\
\text { - } & \text { Growth or change forecast } \\
\text { - } & \text { Environmental systems } \\
\text { - } & \text { Environmental conditions and their } \\
& \text { control } \\
\text { - } & \text { Occupancy } \\
\text { - } & \text { Energy budget }\end{array}$ & 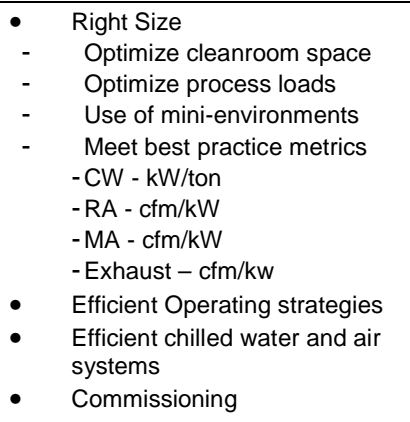 & $\begin{array}{ll} & \text { Reliability } \\
\text { - } & \text { Safe and } \\
\text { comfortable work } \\
\text { environment }\end{array}$ & $\begin{array}{l}\text { - } \\
\text { process and } \\
\text { requiremance } \\
\text { accurately defined to } \\
\text { allow efficient } \\
\text { operation }\end{array}$ \\
\hline $\begin{array}{l}\text { Cleanroom } \\
\text { form } \\
\text { Site plan } \\
\text { Facility } \\
\text { Quality }\end{array}$ & $\begin{array}{l}\text { - } \quad \text { Optimize cleanroom for production } \\
\text { and contamination problem } \\
\text { - } \quad \text { Consider Future Growth } \\
\text { - Consider local geography and } \\
\text { climate }\end{array}$ & $\begin{array}{ll}- & \text { Site Utility Analysis } \\
- & \text { Climate/geographical Analysis } \\
\text { - } & \text { Code and standards Requirements } \\
\text { Process requirements }\end{array}$ & $\begin{array}{ll} & \text { Reduce airflow or increase } \\
\text { HEPA Units with same airflow } \\
\text { Minimize clean Volume, } \\
\text { Static Pressure } \\
\text { - Incremental Build-Out } \\
\text { - Control clean envelop } \\
\text { leakage }\end{array}$ & $\begin{array}{ll}\text { - } & \text { Air Flow Analysis } \\
- & \text { Redundancy } \\
\text { - } & \text { Expansion } \\
& \text { capability }\end{array}$ & $\begin{array}{l}\text { Identify major space } \\
\text { and contamination } \\
\text { considerations and } \\
\text { optimize each for } \\
\text { energy consumption }\end{array}$ \\
\hline $\begin{array}{l}\text { Economy } \\
\text { Initial Budget } \\
\text { Operating } \\
\text { Costs } \\
\text { Life Cycle } \\
\text { Costs }\end{array}$ & $\begin{array}{ll}\text { - } & \text { Efficient Energy Use per Unit of } \\
& \text { Useful Work } \\
\text { - } & \text { Decisions made considering Life } \\
& \text { Cycle Cost } \\
\text { - } & \text { Meet Project Budget Limits }\end{array}$ & $\begin{array}{ll} & \text { Utility (Energy) rate schedules } \\
- & \text { Climate/ geographical impact } \\
- & \text { Company policy on Return on } \\
& \text { Investment }\end{array}$ & $\begin{array}{ll}\text { - } & \text { Meet Process requirements } \\
\text { - } & \text { Perform life cycle cost } \\
\text { analysis } \\
\text { - Lowest energy use per unit of } \\
\text { useful work }\end{array}$ & $\begin{array}{ll}- & \text { Energy budget } \\
- & \text { Project capital } \\
\text { budget }\end{array}$ & $\begin{array}{l}\text { - Evaluate capital cost } \\
\text { and operating cost in } \\
\text { making program } \\
\text { decisions }\end{array}$ \\
\hline $\begin{array}{l}\text { Project } \\
\text { Time }\end{array}$ & $\begin{array}{ll}\text { - } & \text { Provide design time to evaluate } \\
\text { - } & \text { Ffficient options } \\
\text { - } & \text { Facilitate future expansion/retrofit } \\
\text { - } & \text { pricing/peak load reduction } \\
\quad \text { Maintain or improve time to market }\end{array}$ & $\begin{array}{ll} & \text { Design and Construction schedules } \\
- & \text { Growth Projections }\end{array}$ & - Incremental build out & $\begin{array}{ll}- & \text { Growth projection } \\
\text { - } & \text { System life } \\
& \text { expectancy }\end{array}$ & $\begin{array}{ll}\text { - Implications of } \\
\text { change and growth } \\
\text { on long range } \\
\text { energy performance } \\
\text { Minimize peak load/ } \\
\text { cost } \\
\text { Provide reliable } \\
\text { power } \\
\text { - Back-up capability }\end{array}$ \\
\hline
\end{tabular}




\section{Architectural}

The programming process referred to here is described in the book titled "Problem Seeking: An Architectural Programming Primer," by William Pena, et al [1]

Outside of pure luck, the degree of success for any endeavor can be directly related to the preparation that precedes it. The design of a facility is no different. The preparatory phase of facility design is known as programming. An energy efficient design is based upon relevant programmatic information that is timely, accurate, pertinent, and innovative. Considering energy issues during programming is especially important in the design of cleanrooms. While this guide focuses on energy efficiency concepts for cleanroom design it is important to have an understanding of the programming process.

The timing of information in the design process is critical. Untimely input or decisions can cause the project to undergo redesign, to be over budget, to be inefficient, or to be entirely inappropriate. Therefore, programming needs to be the first step in the design process and by focusing on energy issues at this phase, the design team will be able to make integrated decisions that will lead to lower first cost while achieving a high level of energy efficiency. Developing project information and considering energy implications prior to beginning design allows the team to make informed decisions that support other key program requirements and achieve high operating efficiency. Decisions made at the programming phase will direct the design process.

The programming approach described above is both analytical and creative. The analytical aspect of programming involves the collection and examination of pertinent data, beginning with management's objectives for the new cleanroom. This should include input on operating cost as well as first cost, the corporation's environmental concerns, etc. The creative aspect seeks to discover new combinations of ideas from individuals with a stake in the new cleanroom. The results may include new applications of old ideas, concepts adapted from other cleanrooms, or ideas developed with stakeholders during organized brainstorming sessions. In this guide, the elements that have potentially large impacts on energy use are organized into familiar categories so that the programming team can focus on the energy implications with the same importance as other program requirements.

The information developed in this approach provides a framework for decision-making before the design begins. The programming process organizes information to facilitate feedback and evaluation. Data and concepts are often recorded in graphic form, using 5"x 8" analysis cards, which are then organized into a wall display. This provides all interested individuals with an easy to understand, visual reference of programmatic ideas and is easily modified as new information is discovered.

\subsection{Architectural Programming Goals}

One of the general objectives of this guide is to provide ideas for achieving energy efficient environmental systems while maintaining or improving production, quality, comfort, and safety. In order to achieve this goal, the stakeholders must collaborate and coordinate with each other from the beginning. Issues such as optimizing clean space 
allocation, planning for an efficient layout, and developing mechanical system concepts will all require coordinated efforts.

The architectural focus of this guide is to 1) Optimize clean space; 2) Influence an efficient layout of the facility and site; 3) Implement best practices in traditional building systems; and 4) Incorporate efficient specialty architectural components related to cleanrooms.

\subsection{Architectural Facts}

- Codes and standards - Agree on targets to exceed minimum energy code standards.

- Planning for future growth - Provide concepts for efficient incremental growth

- Optimization of clean space - Minimize clean space; utilize optimal cleanliness class; use of mini-enclosures, etc.

- Adjacencies - Plan for adjacency of major equipment

- Building shell efficiency - Utilize best practice design of building envelop to achieve high energy efficiency.

- Coordination for efficient mechanical systems - Early coordination with mechanical engineer to provide space for efficient systems.

- Air management systems - With mechanical engineer, perform preliminary life cycle cost evaluations and trade-offs for air systems.

\subsection{Design Concepts for Energy Efficiency - Architectural Systems}

The architectural team should provide an integrated space plan that provides for efficient product and personnel circulation while providing necessary space for efficient mechanical, process, and electrical systems. Some architectural considerations are as follows:

\subsubsection{Integrate site planning, spatial allocations, and system layout}

The team should plan for efficient system layout considering the following:

- Location of major equipment - close to end use

- Location of central plant - as close as possible to cleanroom

- Location of make-up air systems

- Location of exhaust/scrubber systems;

- Adequate space for efficient equipment

- Adequate space for large piping and ductwork

- Adequate space for efficient return air pathways

- Efficient, low pressure drop cleanroom flooring

\subsubsection{Optimize clean space}

- Define contamination control problem and select cleanliness class(es) to mitigate the problem 
- Minimize clean space

- Consider use of mini-environments and enclosures and lower cleanroom cleanliness requirements accordingly

- Optimize cleanroom ceiling HEPA coverage.

$>$ More coverage for the same airflow will improve efficiency

$>$ Coverage in critical areas to minimize airflow

$>$ Plan for use of computational fluid dynamics (CFD) analysis

- Evaluate cleanroom protocol vs. higher cleanliness;

1.3.3 Implement traditional efficiency measures for building shell and office areas

- Locate major equipment close to end use

- Reduce lighting and cooling loads by maximizing use of daylight

- Use high-performance windows - use glazing with appropriate visible transmittance and shading coefficient

- Apply cutting edge industry references (Also see http://eande.lbl.gov/RLabDG/HELP3493.htm, or http://www.wbdg.org

- Reduce cooling loads through application of best practices in envelop design

- Use appropriate foof coatings (also see http://eetd.lbl.gov/CoolRoofs/)

- Shade impervious surfaces with trees and other landscaping elements.

\section{Mechanical}

\subsection{Mechanical Programming goals}

HVAC systems typically have a lifetime of twenty years or longer, as compared to threeto-five-year return rate of many processes operating in cleanrooms. Implementing energy-efficiency strategies in the design and operation of cleanroom HVAC systems can have lasting beneficial impact on the reduction of energy use, reduction in first costs, and can result in a more reliable cleanroom facility.

The primary programming goals related to mechanical systems are to 1) establish a process to develop accurate process heat load estimates, 2) evaluate air management and chilled water cooling systems; 2) maintain or improve worker comfort and safety; 3) maintain or improve production and quality; and 4) provide design concepts that support "time to market" issues. In order to achieve highly energy efficient HVAC systems, the mechanical engineer must coordinate with the owner and other stakeholders. The team will need to define cleanroom cleanliness and environmental requirements, and then optimize mechanical systems through close coordination with other disciplines. The team must also take into consideration future changes or growth; and current and projected energy pricing.

For mechanical systems serving cleanrooms, areas holding the greatest energy efficiency opportunities are: 1) Efficient Central Plant, 2) Efficient Mechanical Layout, and 3) Efficient Air Systems, For each area, facts important to energy use in energy intensive mechanical systems need to be identified during programming. Based upon these project facts, design concepts are suggested for further investigation by the design team. Where different design options have widely varying energy use (and varying long term operating 
cost) it may be appropriate to conduct preliminary life cycle cost evaluations to aid the program decision-making. While there are some functional requirements that cannot be quantified at the programming phase, most functional requirements can be defined by the use of specific performance metrics. For example, the team may establish design efficiency targets such as $\mathrm{kW} /$ ton for chilled water systems or $\mathrm{cfm} / \mathrm{kW}$ for air systems. These metrics can then be compared to best practices to provide guidance. The programming team can utilize performance metrics to make informed decisions and to set performance targets. Performance metrics for selected systems and components with significant energy use are provided to highlight best practice and comparison to other benchmark data. Examples of their use are summarized in a recent study on cleanroom energy benchmarking [2], The details results can also be downloaded from http://ateam.lbl.gov/hightech/Cleanroom/Benchmarking/.

\subsection{Mechanical Facts}

To design energy efficient mechanical systems that meet process contamination control requirements, the process, contamination sources/effects, environmental requirements, and relevant Codes/Standards must be defined. The topics below are particularly important to be defined during programming:

\subsubsection{Process generated HVAC loads}

Since process heat loads and HVAC recirculation systems account for the majority of environmental energy use in cleanrooms, it is important to determine accurate heat load requirements for the process. This information will dictate the sizing of the most energy intensive mechanical systems and therefore needs to be carefully considered. Most of the heat load to be removed by the HVAC system is input to the cleanroom and surrounding areas by the process occurring in the cleanroom. Heat is generated by converting electrical energy into useful process related work, lighting, fan energy, other plug loads, etc. For this reason, it is appropriate to focus on planned electrical energy use. The project team will eventually determine the total electrical design load, load diversity (loads occurring at the same time), and then establish and understand design margins to account for uncertainty. During programming, all loads will not be known, however estimates will be needed to support planning for space allocation, critical adjacencies, support spaces, etc. In addition, the programming team will identify key needs such as production growth potential that will have a major impact on the design. Defining how process related loads vary over time is critical since the cleanroom HVAC systems and process-cooling systems will remove essentially the entire heat load from the process systems. The design for efficient part load operation will require different strategies than for full load operation. Process utility estimates are typically provided by vendors of process equipment through name plate data, however the project team should carefully examine the information to arrive at actual operating energy requirements. Designer's use of nameplate data to define maximum energy requirements typically results in excessive safety factors by factors of three or more. During detailed design, actual peak operating electrical load should be determined for each piece of process equipment and these loads summed to determine total process load. One method to determine a realistic value is to measure and trend actual electrical load in similar facilities. Benchmark data 
can provide realistic operating load information. If this is not available, equipment vendors should be queried in detail to obtain an accurate load value. Once the total energy requirements are known, a diversification factor must be applied to arrive at actual combined loads. The diversification factor accounts for sequencing and combination of electrical loads. This factor can be applied individually to process equipment, if known, and then the individual diversified loads summed, or an overall diversity can be applied. Once a total diversified load is determined, factors can then be added to account for safety margins, and future growth.

Specific guidance on the margin to be included above the estimated needs should be determined as one of the key program decisions. The design team, including all affected disciplines and the owner's process representative(s) as a group, should make the determination of the amount of margin to include during the programming phase to avoid individually introducing excessive conservatism as each discipline deals with design details later in the design. Traditional design processes often introduce conservatism (margin) that the owner did not intend and may not discover until operation. It is critical that the owner be involved in determining the process utility needs and help to determine the overall margin for uncertainty or growth. This is extremely important in that mechanical equipment may operate extremely inefficiently if operated at part load conditions. Although passive components such as oversized piping and ductwork actually improve efficiency, oversized equipment often operates extremely inefficiently. Strategies which involve over-sizing passive components yet "right sizing" active components can provide reasonable options for future growth and minimize first cost. If process load growth is anticipated due to "ramping up" the process, changes in process technology, or simply production growth, then other strategies need to be explored at the program phase to provide for widely varying load and growth potential, yet allow efficient operation at all levels.

\subsubsection{Contamination control}

Contamination control is the key reason for the cleanroom. The program should therefore revolve around defining the contamination problem. One of the first programming steps then is to define the contamination that is to be controlled or contained by the cleanroom by identifying the unique sensitivities of the cleanroom activity. This is often done by defining critical contaminant quantities and/or contaminant sizes that could adversely affect the activity occurring in the cleanroom. Sources of potential contamination need to be identified, e.g. process equipment, personnel, etc. Definition of potential contamination sources, characteristics, and limits important to the activity in the cleanroom is required in order to define appropriate cleanroom concepts. To achieve an energy efficient design, the contamination control issues needed to support the activity occurring in the cleanroom must be well defined. The most economical solution to the contamination control problem when considering life cycle cost will result in an optimized cleanroom design. Providing more stringent cleanliness than is needed increases capital cost and energy consumption throughout the life of the facility with no offsetting gain in production. 
The team must develop a thorough understanding of the activity to be carried out in the cleanroom, and any impact that specific contaminants can have on that activity. The team can then identify the issues that are most critical to the cleanroom activities. Figure 2 illustrates a typical hierarchy approach of information gathering. First the cleanroom activities (e.g., process, production, etc.) are defined. Then contamination control and environmental requirements are defined, leading to development of cleanroom concepts (e.g., equipment, desired clean space, cleanroom design, etc.). Once these are determined, the overall facility, and finally, the site plan are defined. This approach allows developing an understanding of the functional requirements of the facility before addressing the form of the facility, which is dependent upon them.

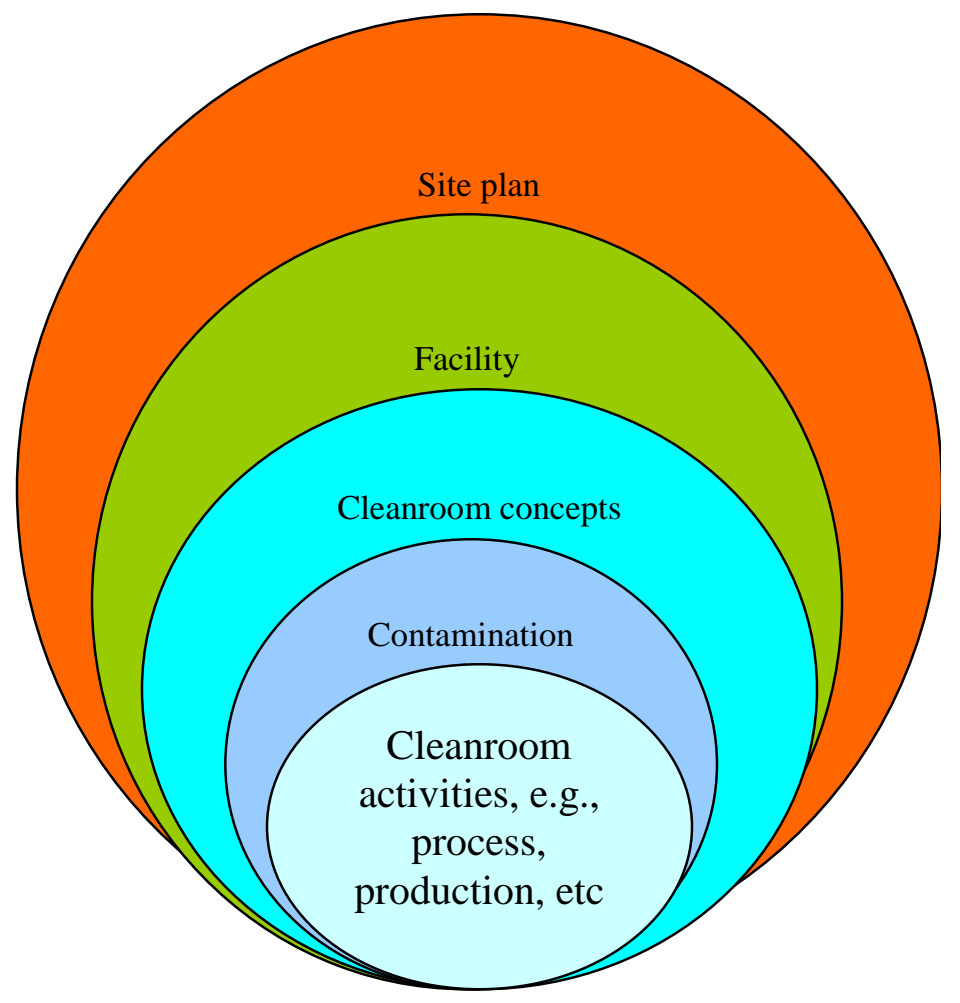

Figure 2 A hierarchy approach of information gathering for cleanroom programming

With a clear understanding of the cleanroom activity and contamination control in the earlier programming steps, the team can develop a series of cleanroom concepts that can meet the full functional requirements of the owner.

\subsubsection{HVAC Systems}

The temperature and humidity requirements for cleanrooms have a direct and significant impact on total energy consumption. Depending upon the application and cleanliness class, the acceptable ranges of environmental conditions (i.e., temperature, humidity, airchange rate, vibration, and noise) for specific zones are defined based on cleanroom 
functions. Recommended air recirculation to achieve various cleanliness classes is defined in the Institute of Environmental Sciences and Technology (IEST) ISO Standards. ISO 14644-1 Cleanrooms and associated controlled environments--Part 1: addresses Classification of air cleanliness (also see http://www.iest.org/publctns/isopubs.htm). The project team also needs to consider more traditional environmental factors such as exhaust requirements, occupant comfort, noise and vibration associated with the HVAC system [3] [4] and [5]).

Make-up air and exhaust systems are determined primarily by applicable codes and their mandated minimum exhaust rates. In addition, Insurers may require minimum exhaust rates that exceed code values. The design must meet or exceed specified rates. For some cleanrooms, ASHRAE Standard 62-1999 may be referenced for make-up air requirements. Currently this standard suggests minimum fresh air change rates for a list of building types including laboratories [3]. There is no data in the standard that specifically addresses make-up air requirements for cleanrooms; however, a minimum of $10 \mathrm{~L} /$ person (20 cfm/person) is suggested for an institutional laboratory, provided that special contaminant control systems be provided for processes. Also refer to [6] and [7] for threshold limit values (TLVs) and biological exposure indices (BEIs). Codes and standards requirements take precedence for many cleanroom applications such as those with hazardous materials ( $\mathrm{H}$ - occupancies) and Biotech or Pharmaceuticals (governed by FDA regulated cGMP requirements).

\subsubsection{Chilled water system}

Chilled water requirements for cleanrooms frequently are determined based upon past experience or gross estimates to allow procurement of long lead-time items such as chillers and pumps. Chilled water system design for a cleanroom project represents a significant opportunity to minimize energy cost for the life of the facility. At the program level, the team needs to carefully define the following:

1. Chilled water temperature - The chilled water system should be designed to operate at the highest temperature possible. Although the design details will be developed later, the design team should adopt this philosophy from the beginning. If small amounts of lower temperature chilled water are determined to be required, there may be significantly less life cycle cost to provide separate point of use chilled water.

2. Level of redundancy - Many cleanrooms provide redundancy for the chilled water system or a portion of the system. Once the need for redundancy is identified (during programming), there are often several design options available to achieve it. For each option, energy efficiency, space requirements, operating flexibility, etc. varies considerably. A simplified life cycle analysis should be used to narrow options for further evaluation. For example, the number and size of chillers can vary depending upon the team's approach to redundancy.

3. Part load operation - In many cleanrooms, full process loads are developed over a considerable "ramp-up" period resulting in long periods of operation at part load conditions. In addition, process changes, or production increases may impact the overall chilled water needs. The chilled water plant and its associated components need to be sized to allow efficient operation at the various load conditions that the plant may see 
over time. This will affect space planning, sizing of components and distribution systems, chiller types, control strategies, etc. and should be considered in the program.

4. Efficiency targets - Chillers and chilled water systems energy efficiency issues are well documented in the literature and industry publications. In addition, benchmark data is available to provide guidance. The program team should establish efficiency targets for the major chilled water components and the overall system. Targets for part load and full load operation should be established. These become guidelines for the designers during detailed design.

5. Future expansion - To establish a strategy for future growth, the project team needs to consider the following:

1) Estimated current and future process loads - Various methods can be used to estimate process loads. These include using actual load from similar process systems, using load density $(\mathrm{kW} / \mathrm{sq} \mathrm{ft})$ estimates, or developing detailed process equipment utility requirements. Each of these methods can yield appropriate design values but careful consideration of actual load vs. name-plate values, load diversity, and conservatism factors must be included. The estimated timing for additional load is also important and can be used to delay capital expenditure until load growth occurs.

2) Efficient part load operation - Variable speed devices and/or incremental build-out will allow the systems to operate efficiently initially and as additional process load is added. Future connection strategies to add additional capacity such as adding additional pumps, chillers, etc. without impacting operation should be addressed in the program.

3) Sizing of passive distribution systems for maximum flows - Piping, Ductwork, and Electrical wiring systems should be sized for the maximum anticipated flow or current. Sizing these elements for the maximum conditions will result in efficient operation at part load conditions.

4) Space and access required for future equipment - Adequate space for future expansion and appropriate adjacency to existing systems should also be addressed in the program.

Guidelines for chilled water systems and components are well documented. Some representative information can be found at the following websites:

http://www.hvacexchange.com/cooltools/guides_frm.htm

http://www.eren.doe.gov/femp/procurement/begin.html

http://www.energydesignresources.com/publications/design_briefs/index.html

\subsubsection{Climatic and geographic factors}

Localized climatic and geographic factors can sometimes have a large influence on the site layout and the building itself. A good understanding of system energy implications due to climatic and geographic information can lead to more efficient mechanical system design. For example, the design of the make-up air supply and exhaust for cleanrooms will be based on outside air ventilation rates, yearly temperature and humidity data, while considering any site constraints due to local geography. The team should specify the most optimal condenser water temperature, using free cooling, and use of efficient 
humidity control. Microclimate analysis can be conducted when needed in combination with published weather data, which are available from a variety of sources. External airflow analysis is required to determine location of air intake and exhaust when considering discharge of potentially hazardous materials. The results of this study may have an effect on space allocation, placement of intakes and exhausts, efficient distribution, etc.

\subsubsection{Availability and price of energy - Life-cycle-cost analysis}

An analysis of reliability and available energy options should be performed to determine a range of possible rates and uncertainties. These rates will be used to perform preliminary life cycle cost analysis for key decisions. The cleanroom owner will need to define policy for considering return on investment (ROI), or cost of ownership models to be used for life cycle cost analysis. An example of a building life cycle cost analysis tool is provided at the following website:

http://www.eren.doe.gov/femp/techassist/softwaretools/softwaretools.html - blcc

\subsection{Design Concepts for Energy Efficiency - Mechanical Systems}

A fundamental energy efficiency concept for mechanical systems or components is to achieve the most useful work for the least amount of energy (lowest energy cost). To achieve a design with the lowest energy use, the programming team should focus on the following:

\subsubsection{Efficient central plant}

\subsubsection{Concepts for design of an efficient central plant}

- Design for real heat load requirements (see earlier discussion)

- Define appropriate environmental requirements - contamination, temperature, humidity, vibration, and noise level;

- Consider strategies for potential growth - incremental build-out, extra valves, etc.;

- Use free cooling whenever feasible;

- Design efficient chilled water system

- chiller sizing

- part load efficient pumping

- cooling towers

- refrigerant specification

- dual temperature loop vs. single loop

- minimization of flow resistance, i.e. pressure drop

- load vs. chiller rating close to one

- optimized chilled water temperature

- target system and component efficiency in $\mathrm{kW} /$ ton

- Design efficient pumping systems

- Pump efficiency

- Motor efficiency 
- Pipe sizing and layout to minimize resistance. Larger piping and minimizing fittings or providing space for large diameter bends improves efficiency.

- Design efficient boiler systems

- Boiler efficiency

- Avoid use of high pressure boilers (operator issue, code issue)

- Humidification schemes

- Redundancy, back-up, and normal operation efficiency- Take advantage of redundant equipment for efficient normal operation.

- Layout major ductwork and piping then major equipment to minimize flow resistance

- Study alternative systems and perform life cycle analysis through use of appropriate metrics.

\subsubsection{Efficient mechanical layout}

Mechanical and architectural coordination is important to achieve layouts that are energy efficient. The space available for mechanical systems will often dictate the economics, types, sizes and capacities of individual components. Space for mechanical equipment, ductwork, and piping may also impact system reliability, maintenance, and system flexibility for immediate or future needs.

\subsubsection{Mechanical layout defign concepts}

Design concepts for efficient mechanical layout include the following:

- Estimate and determine equipment sizing and resulting space requirements

- Interact with architect to allocate space for major equipment such as large pipes and ducts

- Develop strategies for potential future growth

\subsubsection{Efficient air systems}

Maintaining cleanroom cleanliness conditions requires a tremendous amount of air circulation. Fan power is a major contributor to energy demand in these air systems. Since fan power is used to overcome system resistance in the air delivery system, and in theory fan power is proportional to the cube of air velocity, even a slight reduction in air velocity will result in considerable decrease in fan power. For example, a 10\% reduction of supply airflow would theoretically require roughly $30 \%$ less power for the supply fan to transport the air. Consideration should be given to

- Achieving low pressure drop while meeting the required air supply;

- Utilizing energy-efficient components as well as appropriate duct and air recirculation path sizing;

- Adopting efficient control methods such as variable volume air (VAV) when appropriate; and

- Minimizing and avoiding energy losses induced by cleanroom envelope air leakage 


\subsubsection{Air Systems Deeign Concepts}

The project team needs to consider specific strategies and techniques to achieve efficient make-up, recirculation, and exhaust systems. The reduction of resistance to airflow (pressure drop) in air delivery systems is a key consideration. Pressure loss should be kept as low as possible through low-velocity sizing of ducts, coils, filters, and other components. This can be achieved by design that minimizes changes of direction, and provides layouts that minimize use of fire dampers, etc. Because air leakage from ducts can induce considerable energy losses, the programming team should consider measures to minimize duct lengths and pay particular attention to duct routes. The following concepts should be considered whenever feasible.

\subsection{Efficient make-up air systems}

Make-up air systems represent an excellent opportunity for improving efficiency. The programming team should consider the following factors in developing make-up air system concepts.

- Reduce delivery pressure loss by operating at low air handler face velocity;

- Provide for optimal air-flow and reduce fan power by use of Variable Speed Drives (VSD's);

- Plan for use of efficient filters;

- Locate make-up air handlers as close to cleanroom as practical. Consider pressure drop, material cost, noise, and vibration for optimum location. Life cycle cost analysis may be warranted.

- Implement accurate temperature and humidity control

- Minimize exhaust and pressurization (losses) so as to minimize make-up air. Understand process exhaust requirements and account for diversity.

\subsection{Efficient air recirculation systems}

Different air Recirculation system configurations should be evaluated. Different recirculation systems have widely varying energy use.

Figure 3 shows actual benchmark results for efficiency of several types of systems.

During the programming phase, the team may consider the use of advanced cleanroom airflow modeling to assist in determining ceiling coverage, and airflow rates. Through this type of analysis, it is possible to minimize air change rates resulting in significant energy reductions.

Recirculation air systems for cleanroom designs can maximize energy savings by reducing airflow rate and the pressure drop in the air recirculation loop. Significant energy savings are also possible when high-efficiency components are used for circulating the large quantities of air.

- Consider advantages and disadvantages of different types of air recirculation concepts (e.g., fan-filter; plenum, ducted HEPA, fan-tower, return from under floor or sidewall, etc.); For a comparative discussion of air management systems see the reference [11] and another article by Grout, also see 
http://cr.pennnet.com/Articles/Article_Display.cfm?Section=Archives\&Subsection= Display\&ARTICLE_ID=95027\&KEYWORD=recirculation\%20systems\&x=y.

- Consider controls that allow air flow reduction when cleanrooms are unoccupied;

- Minimize recirculation airflow - Specify minimal IEST recommended values for air change requirements when appropriate for the process;

- Use high efficiency HEPA or ULPA filters.

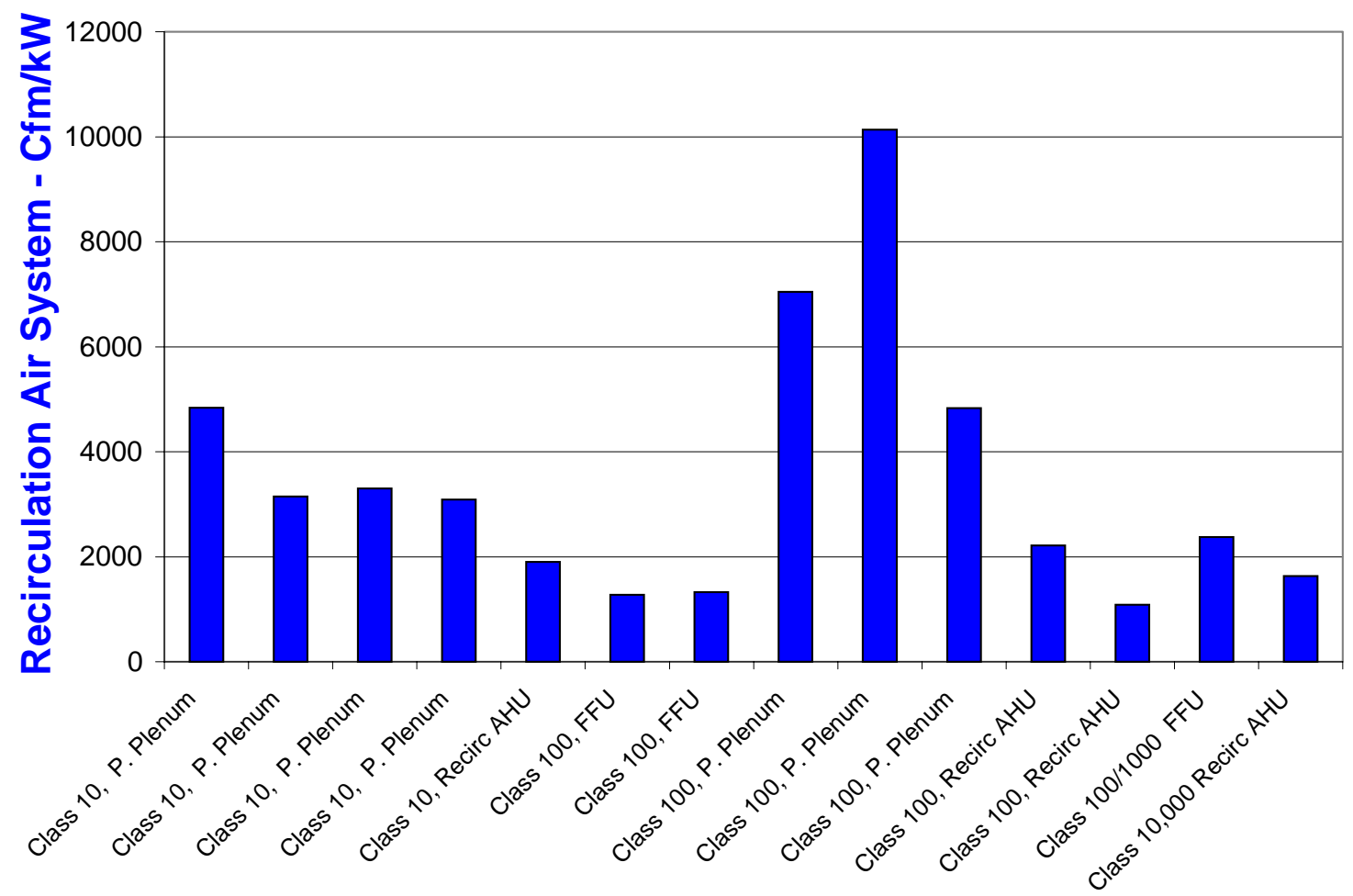

Figure 3 Recirculation System Efficiency

\subsection{Efficient exhaust systems}

- Comply with code requirements but avoid excessive exhaust - consider re-use of nontoxic exhaust;

- Apply multiple exhausts as compared to a single exhaust to reduce space and fan energy use;

- Optimize exhaust air velocity. Provide adequate velocity to avoid re-entrainment yet not exceed needs.

- Consider heat recovery from exhaust systems

\subsection{Special equipment}

- Evaluate Scrubbers/filters for efficiency. 
- Evaluate the need for burn-boxes or other exhaust options.

\subsection{Functional requirements for mechanical systems}

Every decision during programming must lead to designs that meet applicable Codes and Standards. The project team should also define and use metrics whenever possible to set design targets and quantify energy implications. In the Appendices section, a list of metrics important to cleanroom energy use is presented.

The following is a brief description on the functional requirements for mechanical system design.

\subsubsection{Functional requirements to achieve an efficient central plant}

To establish functional requirements for chilled water systems, the project team needs to identify the resources for chiller selections, based on application types, critical design values (e.g., entering condenser water temperature, evaporator leaving water temperature, flow rates, etc.), and available equipment on the market.

Similar to chiller efficiency (also see http://www.eren.doe.gov/femp/procurement), use $\mathrm{kW} /$ ton as the metric for the performance of chilled water systems. Adding the energy used for chilled water pumps, condenser water pump and cooling tower, a state-of-the-art chilled-water system has an efficiency of about $0.54 \mathrm{~kW} /$ ton [8]. Planned incremental build-out and/or part load operation should consider the part load operation to design an efficient plant. For chiller information, refer to Air-Conditioning \& Refrigeration Institute (ARI) - also see http://207.140.180.11/ari-prog/direct.nsf, which publishes standards and directories of chillers and other air-conditioning equipment.

Benchmark results for several operating cleanroom chiller systems are shown in Figure 4.

Chilled water system performance can vary significantly and the programming team should establish target metrics and general design philosophy so as to achieve an efficient design.

To establish functional requirements for efficient pumping systems, the project team can use pump energy efficiency, electrical energy demand $(\mathrm{kW})$ used by pumps per unit of flow rate delivered (gallons per minute), as the target metric. This will determine the appropriate minimum efficiency level (kW/GPM). The project team can recommend other strategies for efficient pumping system design (e.g., lower water flow, less friction loss, variable frequency drive), and require optimal efficiency pumps.

To establish functional requirements for efficient boiler systems, the loads need first to be optimized, and then the boiler(s) need to be selected to minimize cost of ownership. The loads (preheat, reheat, and humidification) should be optimized to minimize the amount of reheat required, and then to minimize the temperature of the heat required. For example, atomizing-type humidifiers with larger heating water coils should be considered instead of steam-powered humidifiers; preheat and reheat coils should be designed for low return water temperatures to allow the use of highly efficient boilers with condensing heat exchangers. Overall boiler efficiency should be considered (including steady-state and standby); boilers that are designed for cold standby and rapid startup greatly reduce 
standby losses. If more than one temperature is required (and especially where steam and hot water are both needed), consider splitting the boiler plant so that only the necessary temperature is delivered to each load.

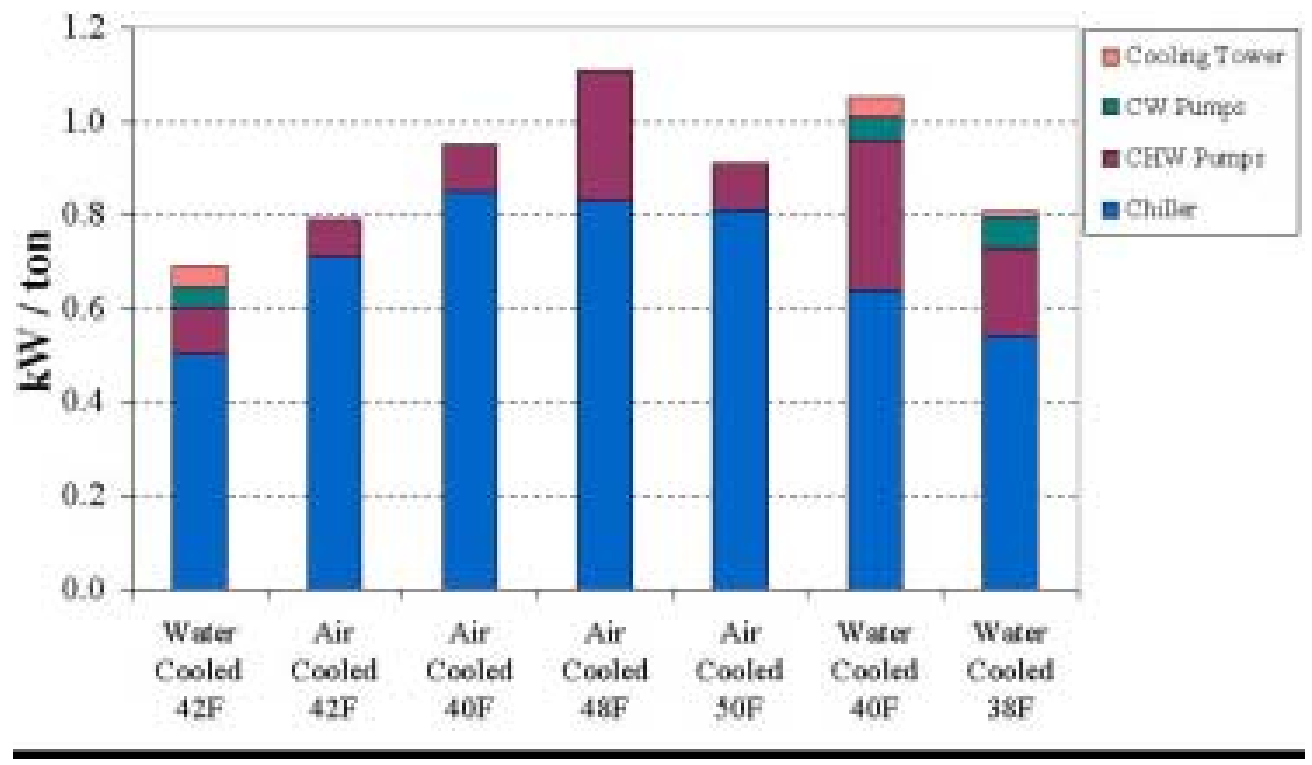

Figure 4 Chilled Water System Energy Efficiency

\subsubsection{Functional requirements for efficient mechanical layout}

To determine the space requirements for HVAC systems, the project team will develop the relationship between system size (e.g., ducts, pipes) and its efficiency because these factors are tied directly to system economics (i.e., first cost, and operating cost). The project team members (e.g., mechanical engineers, architects, and owners) need to interact closely and make informed decisions as to space layouts.

Examples economic analysis on pumping cost through optimum piping sizing. Also see http://www.pumps.org/acb/showdetl.cfm?\&DID=9\&ObjectGroup_ID=247\&Product_ID $=373 \&$ CatID $=35$

\subsubsection{Functional requirements for efficient air systems}

To achieve energy-efficient air systems (also see http://eande.lbl.gov/RLabDG/HELP3219.htm), specific system approaches can be defined utilizing the design concepts described above. Another consideration once the systems are efficiently sized is to select highly efficient components for use in the mechanical air systems. Utilizing existing benchmarking data will guide selection of energy-savings options [9].

A study has shown up to $7 \%$ of cleanroom electricity usage can be realized by requiring a low system pressure drop. This includes use of low face-velocity cooling coils, low 
velocity in ducts, return air chases, and filters. Implementing low face velocity in air delivery systems has been shown to achieve an attractive return on investment (ROI) [10].

The study has also shown that the use of variable-speed drives (VSD's) for air recirculation, make-up, and exhaust fan motors can result in up to 15-30\% energy saving over constant-speed drives. Other energy related considerations when planning for air delivery such as use of ducts or plenums, duct sizing and shape, and materials of construction all have large impact on efficiency.

\subsection{Preliminary budgeting}

Establishing a preliminary budget is often part of the programming process. To achieve an energy efficient design, the programming team must establish a life cycle cost (or return on investment) evaluation process.

- Life cycle savings: Federal life cycle cost guidance also see http://www.eren.doe.gov/femp/aboutfemp/pdfs/lifecycleguidance.pdf

- Simple payback

- Return on investment (ROI) 


\section{Electrical}

\subsection{Electrical Programming Goals}

The primary goal addressed in this guide for electrical is to plan for an efficient and reliable electrical power supply and distribution system, and to provide efficient lighting throughout the facility. Other electrical system design considerations such as emergency lighting, etc. are not addressed since they are either mandated or have very little impact on energy use.

Lighting for non-cleanroom spaces should follow accepted efficiency practices. For further lighting information, see LBNL Laboratory Design Guide.

\subsection{Electrical Facts}

The design of the electrical distribution system has direct impact on first costs as well as operation and maintenance costs. Process load diversification and guidance on design conservatism are important for the correct sizing of electrical systems. Design concepts for energy efficient electrical systems

- Arrangement and sizing of electrical distribution systems

The arrangement of the distribution system includes defining the system voltage levels and then addressing the physical arrangement of feeders. Planning at the program level should define that electrical loads be accommodated at the highest practical voltage (typically 480 volts for motor loads, 277 volts for lighting) to minimize losses in the transformers and feeders. Space planning for an efficient physical arrangement is also important to minimize both first and operating costs. The goal should be to keep feeders as short as possible and transformers as close to loads as possible.

Distribution system sizing should take into account the initial and projected loads (see following section) and should be able to accommodate both partial loads and full loads in an efficient manner. Feeder sizes should be selected to minimize total life cycle costs, keeping in mind that the National Electrical Code (also see http://www.nfpa.org/Home/index.asp) sizing requirements are for fire protection and motor starting and are usually smaller than optimal for life cycle cost minimization. When planning for future loads, provide switchgear and breakers to allow new transformers and equipment to be added without requiring shutdowns. Consider multiple transformers with inter-tie switching rather than one necessarily oversized transformer for a particular load; this arrangement can maximize both transformer part-load efficiency and system reliability.

Load monitoring capability of distribution equipment should be employed to help establish baseline and trend information.

- Process Load Diversification and Design Conservatism

When determining electrical loads, while the equipment nameplate ratings must be accommodated, an important consideration is that most equipment operates well below 
maximum rating most of the time. In addition, some equipment cycles on and off, and other equipment is used only occasionally for special functions. This part-load operation results in a load diversity that must be considered in system sizing. This is especially important for transformers, where over sizing is inefficient. The team needs to be aware of design conservatism in manufacturer ratings and the distribution system. As with the mechanical loads, it is important that all safety factors be explicitly stated and understood by all concerned parties. The programming team should set the overall level of conservatisms.

- Efficient transformers;

Transformer loading and design are important for efficient transformer operation. Since transformer losses vary with the load, it is important to know the rated no-load and fullload losses from which operating efficiency can be easily determined for range of loads expected. This efficiency can then be used to minimize life-cycle cost.

The EPA Energy Star website provides information on highly efficient transformers. (also see

http://yosemite1.epa.gov/estar/consumers.nsf/content/transformers_gateway_page.htm

- Efficient motors;

Once the process and mechanical loads have been accurately estimated (see Mechanical) further savings can be achieved by the specification of efficient motors. A good start is to specify premium efficiency motors. To optimize the selection, the highest efficiency motor for the design load should be specified. In addition, motor speed for constantspeed applications needs to be considered. Since part-load curves and slip speeds vary between manufacturers, it pays to carefully consider planned operation. For selecting new motors, the MotorMaster database (also see http://mm3.energy.wsu.edu/mmplus/) is helpful, since it allows easy comparisons between motors. Another area of savings for motors that operate at constant speed is to use motor starters with electronic overloads rather than thermal overloads. Such starters provide better overload and phase loss protection while also using less energy in the starter itself. For general information on improving efficiency in motor systems, see the DOE's website. also see http://www.eren.doe.gov/EE/industry_motors.html

- Efficient lighting

- Make use of conventional lighting controls

- Specify addressable lighting controls

- Investigate use of new technology such as light pipes http://www.3m.com/market/construction/html/products/product194_p.html\#Dra wings

- Investigate task lighting where appropriate

- Use of daylighting (perimeter and offices)

- Use of efficient lighting fixtures.

While lighting is typically a relatively small part of the total electricity use of a cleanroom facility, there are still significant energy efficiency opportunities in this area. Targets for lighting W/square foot and $\mathrm{kWh} / \mathrm{yr}$ should be established to guide the design. 
Occupancy and daylighting controls, remote fixtures with light pipes, and efficient general lighting in combination with task lighting should all be considered.

Automatic (motion sensor or timed) controls can greatly decrease energy used during unoccupied times. Safety concerns from false "offs" can be addressed through the use of manually switched task lighting and uncontrolled emergency fixtures. Especially in perimeter support and office areas, where windows can be provided to allow access to natural light, the use of daylighting in combination with automatic dimming controls should be considered.

Lighting systems for the cleanroom area can be distributed (fixtures in the room) or centralized, using a highly efficient source and a light-pipe distribution system. The centralized systems are a maintenance advantage since they get the lamps and ballasts out of the clean room; in EMF-sensitive areas, they greatly reduce the lighting contribution to EMF.

\section{Control}

\subsection{Control Systems Programming Goals}

The goal of an efficient and reliable control system is to maximize the overall efficiency of cleanroom operation and production, while maintaining or improving production, quality, reliability, safety, and cost effectiveness. Specific goals may include:

- Open protocol systems

- Ability to tune system response to load

- Adequate monitoring capability

- Ability to adjust cleanroom airflow

- Optimize heating, cooling, and humidification

- Optimize central plant systems operation

\subsection{Control Facts}

Whether or not the mechanical systems, process and electrical systems can effectively achieve high energy-efficiency in cleanrooms largely depends on the design of control systems. It is essential to design and implement efficient, robust and reliable control systems in cleanroom design. To achieve the programming goals, control engineers not only need to work closely with mechanical engineers, but also need to have early involvement with the project team.

\subsection{Design Concepts for Energy Efficiency - Control Systems}

The following concepts can be applied to support the control system design for energy efficiency.

- Early involvement

Typical construction projects involve the control designer relatively late in the design process and the commissioning agent even later. However, it is important for the involvement of both of these critical parties to start as early as possible in the design of the mechanical and electrical systems so that coordination is facilitated. This coordination pays dividends in getting a system operating correctly with a minimum of delays. 
- Open protocols

Consideration should be given to specifying open protocols, such as BACnet][12] (also see http://www.bacnet.org/, and LonWorks (also see http://www.lonworks.com/). Open protocols are useful in that they allow equipment from multiple control vendors to be used in a single system, either at the time of initial construction or over time. If controls are to be sole-sourced at the facility (or all facilities of the owner, depending on how control monitoring is done), open protocols are less useful.

- Local vs. central Control

The degree of control centralization should be decided during project programming. The trend is toward ever-more decentralized control, with each piece of controlled equipment getting a dedicated controller, in turn monitored and supervised by a central system. Such systems give maximum reliability and flexibility, since the local control can continue to function if there are failures elsewhere in the system, and the central monitor can detect and alarm failures in the local units.

- Minimize simultaneous heating and cooling (dehumidification/humidification)

A key goal in programming the control system is to minimize the use of energy to fight another use of energy. The most common examples are cooling and subsequent reheating; dehumidification and humidification. The details of mechanical system configurations will determine how best to meet this goal, but in general resetting temperatures in upstream air and water systems to just meet the needs of the downstream systems is a good place to start.

- Use of parallel equipment

Cleanroom facilities typically have many pieces of parallel equipment, and the overall efficiency of the plant depends on the operating strategy. Part-load efficiencies should be studied to determine how many units should be operated at any given load. For example, typically extra cooling tower cells with variable-speed fans can be used to improve efficiency, even at relatively light loads, whereas extra chillers operating at light load tend to decrease efficiency.

- Monitoring capability

In order to manage the performance and efficiency of the facility, it is necessary to provide information to the operator. A key design concept should include a requirement for direct monitoring capability of all key performance metrics $(\mathrm{kW} /$ ton for the chiller plant, $\mathrm{W} / \mathrm{ft}^{2}$ for lighting, etc.). The controls should be capable of real-time data display, data export, data trending and archiving.

- Optimal control strategies

Consider using optimal control strategies to control multi-variable systems such as chiller

plants. Such strategies can greatly reduce energy use by optimizing the combination of such variables as tower water temperatures and flow, versus chiller compressor power, under varying process and ambient load conditions. See LBNL Laboratory Design Guide

- Airflow reduction when unoccupied

Consider reducing cleanroom airflow when the room is unoccupied. 


\section{References}

[1] P. William, et al. 1987. Problem Seeking: An Architectural Programming Primer 3rd edition (October 1987), American Institute of Architects; ISBN: 0913962872.

[2] Applications Team. 2001. High-tech Buildings - Market Transformation Projects. Final Report to CIEE and PG\&E. LBNL-49112.

[3] ASHRAE. 1999. ANSI/ASHRAE Standard 62-1999, "Ventilation for acceptable indoor air quality and addendum," American Society of Heating, Ventilating, and Air-conditioning Engineers, Inc. Atlanta, GA.

[4] ASHRAE. 1992. ANSI/ASHRAE Standard 55-1992, "Thermal environmental conditions for human occupancy and addendum," American Society of Heating, Ventilating, and Air-conditioning Engineers, Inc. Atlanta, GA.

[5] ASHRAE Standard 68-1997 (AMCA Standard 330-97), "Laboratory methods of testing to determine the sound power in a duct," American Society of Heating, Ventilating, and Air-conditioning Engineers, Inc. Atlanta, GA.

[6] ACGIH. 2001. Industrial Ventilation: A Manual of Recommended Practice, 24th Edition. American Conference of Governmental Industrial Hygienists, 1330 Kemper Meadow Drive, Cincinnati, Ohio 45240.

[7] ACGIH. 2001. Threshold limit values and biological exposure indices. American Conference of Governmental Industrial Hygienists, 1330 Kemper Meadow Drive, Cincinnati, Ohio 45240, 513-742-2020.

[8] Robertson, C. 2000. Opportunities for energy efficiency in clean rooms: strategic drivers and responses. Cleanrooms West 2000 Conference Proceedings: 347-353, Penn Well Corporation, Oregon Convention Center, October 2-4. www.cleanrooms.com

[9] Tschudi, W. 2000. Energy benchmarking in cleanroom facilities. Cleanrooms West 2000 Conference Proceedings: 387-399, Penn Well Corporation, Oregon Convention Center, October 2-4. www.cleanrooms.com

[10] Owen, G. 2000. Low face velocity: an energy conservation option for makeup air units. Cleanrooms West 2000 Conference Proceedings: 355-363, Penn Well Corporation, Oregon Convention Center, October 2-4. www.cleanrooms.com

[11] Matsuki M., and N. Tanaka. 1998. Energy Saving System for Air Conditioning of Clean Room for Semiconductor Factory (Estimation of FMU System), Special Issue on Global Environment, Number 160 Volume 63 January, Oki Electric Industry Co., Ltd.

[12] ASHRAE. 1995. ASHRAE Standard 135-1995 A Data Communication Protocol for Building Automation and Control Networks. 1995. 


\section{Useful Links and Related Publications}

\section{Weather Data Sources}

- National climatic data center.

- ASHRAE weather data in CD ROM

- The Regional Climate Centers

- Gas Technology Institute

\section{Links to other documents}

- Benchmarking of energy use in cleanrooms (also see http://ateam.lbl.gov/hightech/Cleanroom/Benchmarking//)

- LBNL Laboratory Design Guide, also see http://eande.lbl.gov/RLabDG/HELP3.HTM

- Whole Building Design Guide, see http://www.wbdg.org

- Building Envelope Techniques, such as Roof coatings (also see http://eetd.lbl.gov/CoolRoofs//

- ISO 14644-1 Cleanrooms and associated controlled environments--Part 1: addresses Classification of air cleanliness (also see http://www.iest.org/publctns/isopubs.htm).

- Guidelines for chilled water systems and components:

- http://www.hvacexchange.com/cooltools/guides frm.htm

- http://www.eren.doe.gov/femp/procurement/begin.html

- http://www.energydesignresources.com/publications/design_briefs/index.html

- Building life cycle cost analysis tool:

- http://www.eren.doe.gov/femp/techassist/softwaretools/softwaretools.html - blcc

- Economic analysis on pumping cost through optimum piping sizing:

- http://www.pumps.org/acb/showdetl.cfm?\&DID=9\&ObjectGroup_ID=247\&Prod uct ID=373\&CatID=35

- Life cycle savings: Federal life cycle cost guidance, also see http://www.eren.doe.gov/femp/aboutfemp/pdfs/lifecycleguidance.pdf

- Energy-efficient air systems (also see http://eande.lbl.gov/R-LabDG/HELP3219.htm

- Air management

- http://cr.pennnet.com/Articles/Article_Display.cfm?Section=Archives\&Subsectio $\mathrm{n}=$ Display\&ARTICLE_ID=95027\&KEYWORD=recirculation\%20systems $\& \mathrm{x}=\mathrm{y}$

- Chiller efficiency (also see http://www.eren.doe.gov/femp/procurement)

- Air-Conditioning \& Refrigeration Institute (ARI) - also see http://207.140.180.11/ariprog/direct.nsf

- National Electrical Code (also see http://www.nfpa.org/Home/index.asp) sizing requirements are for fire protection and motor starting

- The EPA Energy Star website on highly efficient transformers.

- http://yosemite1.epa.gov/estar/consumers.nsf/content/transformers gateway page htm

- MotorMaster database (also see http://mm3.energy.wsu.edu/mmplus/

- Improving efficiency in motor systems, see http://www.eren.doe.gov/EE/industry_motors.html 
- New technology such as light pipes, see http://www.3m.com/market/construction/html/products/product194_p.html\#Drawing: s

- Open control protocols, such as BACnet (also see http://www.bacnet.org/, and LonWorks (also see http://www.lonworks.com/. 


\section{Cleanroom Metrics}

\begin{tabular}{|l|c|}
\hline Description & Units \\
\hline $\begin{array}{l}\text { Recirculation Air Handler Unit (RAH) } \\
\text { Efficiency }\end{array}$ & $\mathrm{cfm} / \mathrm{kW}$ \\
\hline $\begin{array}{l}\text { Make-up Air Handler (MUA) } \\
\text { Efficiency }\end{array}$ & $\mathrm{cfm} / \mathrm{kW}$ \\
\hline $\begin{array}{l}\text { Annual Energy Cost per } \\
\text { Cleanroom Square Foot }\end{array}$ & $\mathrm{MBtu} / \mathrm{ft}^{2} / \mathrm{yr}$ \\
\hline Annual Fuel Usage & $\mathrm{kWh} / \mathrm{ft}^{2} / \mathrm{yr}$ \\
\hline Annual Electricity Usage & $\mathrm{MBtu} / \mathrm{ft}^{2} / \mathrm{yr}$ \\
\hline Annual Energy Usage & $\mathrm{cfm} / \mathrm{ft}^{2}$ \\
\hline Make-Up Air & $\mathrm{cfm} / \mathrm{ft}^{2}$ \\
\hline Recirculation Air & $\mathrm{ACH} / \mathrm{hr}$ \\
\hline Recirculation Air Change rate & $\mathrm{ACH} / \mathrm{hr}$ \\
\hline Ventilation Air Change rate & $\mathrm{ft} / \mathrm{ton}$ \\
\hline Cooling Load Density & $\mathrm{W} / \mathrm{ft}^{2}$ \\
\hline Process equipment Power Density & $\mathrm{W} / \mathrm{ft}^{2}$ \\
\hline Lighting Power Density & $\mathrm{cfm} / \mathrm{kW}$ \\
\hline Exhaust System Efficiency & \\
\hline
\end{tabular}

Cleanroom Energy Usage Breakdown

\begin{tabular}{|l|c|}
\hline Parameter & Units \\
\hline Total Recirculation Fan Power & $\mathrm{kW}$ \\
\hline Total Make-Up Air Handler Power & $\mathrm{kW}$ \\
\hline Total Process Power & $\mathrm{kW}$ \\
\hline Chilled Water Plant & $\mathrm{kW}$ \\
\hline Other Power Usage & class rating per ISO 14644-1 \\
\hline Cleanroom cleanliness & cfm \\
\hline Cleanroom Recirculation Flow & Deg F $+/-\%$ \\
\hline $\begin{array}{l}\text { Cleanroom Temperature and } \\
\text { tolerance }\end{array}$ & Relative Humidity $+/-\%$ \\
\hline Humidity Conditions and tolerance & \\
\hline
\end{tabular}


CLEANROOM ENERGY PROGRAMMING GUIDE

\begin{tabular}{|l|c|}
\hline Annual Electricity Use & $\mathrm{kWh} / \mathrm{yr}$ \\
\hline Annual Fuel Use & Therm/yr \\
\hline Peak Power & $\mathrm{kW}$ \\
\hline Average Power Factor & $\%$ \\
\hline Facility Area & $\mathrm{ft}^{2}$ \\
\hline Cleanroom Area & $\mathrm{ft}^{2}$ \\
\hline
\end{tabular}

\section{Make-Up Air}

\begin{tabular}{|l|c|}
\hline Parameter & Units \\
\hline Make-up Air Flow & $\mathrm{cfm}$ \\
\hline MUA Fan Power & $\mathrm{kW}$ \\
\hline System Pressure Drop & Inches of static \\
\hline Coil Face Velocity & $\mathrm{fpm}$ \\
\hline
\end{tabular}

\section{Recirculation Air Handlers}

\begin{tabular}{|l|c|}
\hline Parameter & Units \\
\hline Recirculation Air Flow & $\mathrm{cfm}$ \\
\hline Recirculation Fan Power & $\mathrm{kW}$ \\
\hline System Pressure Drop & Inches of static \\
\hline $\begin{array}{l}\text { Air Velocity across filters and coil in } \\
\text { air handler }\end{array}$ & $\mathrm{fpm}$ \\
\hline Pressurization & Inches of static \\
\hline Cooling Load & Tons \\
\hline
\end{tabular}

\section{Exhaust}

\begin{tabular}{|l|c|}
\hline Parameter & Units \\
\hline Total Air Flow & $\mathrm{cfm}$ \\
\hline Fan Power & $\mathrm{kW}$ \\
\hline Fan Pressure Rise & Inches of static \\
\hline
\end{tabular}




\section{Central Plant - Chilled Water Plant Metrics}

\begin{tabular}{|l|c|}
\hline Description & Units \\
\hline Chiller Efficiency & $\mathrm{kW} / \mathrm{ton}$ \\
\hline Tower Efficiency & $\mathrm{kW} / \mathrm{ton}$ \\
\hline Condenser Water Pumps Efficiency & $\mathrm{kW} / \mathrm{ton}$ \\
\hline Chilled Water Pumps Efficiency & $\mathrm{kW} / \mathrm{ton}$ \\
\hline Total Chilled Water Plant Efficiency & $\mathrm{kW} / \mathrm{ton}$ \\
\hline Plant Efficiency While Free Cooling & $\mathrm{kW} /$ ton \\
\hline
\end{tabular}

\section{Chilled Water Plant}

\begin{tabular}{|l|c|}
\hline Parameter & Units \\
\hline Chiller Power & $\mathrm{kW}$ \\
\hline Primary Chilled Water Pump Power & $\mathrm{kW}$ \\
\hline Secondary Chilled Water Pump Power & $\mathrm{kW}$ \\
\hline Chilled Water Supply Temperature & Deg F \\
\hline Chilled Water Return Temperature & Feet of head \\
\hline Chilled Water Head $(\Delta \mathrm{P})$ & $\mathrm{gpm}$ \\
\hline Chilled Water Flow & $\mathrm{kW}$ \\
\hline Cooling Tower Power & Feet of head \\
\hline Condenser Water Head & $\mathrm{kW}$ \\
\hline Condenser Water Pump Power & Deg F \\
\hline Condenser Water Supply Temperature & Feet of head \\
\hline $\begin{array}{l}\text { Process Cooling Pressure Drop across } \\
\text { Pumps ( } \Delta \text { P) }\end{array}$ & $\mathrm{kW}$ \\
\hline Process Cooling Water Pumps Power & $\mathrm{gpm}$ \\
\hline Process Cooling Flow & Deg F \\
\hline Process Cooling Supply Temperature & \\
\hline
\end{tabular}


CLEANROOM ENERGY PROGRAMMING GUIDE

\begin{tabular}{|l|c|}
\hline Process Cooling Return Temperature & Deg F \\
\hline Chiller Cooling Load & Tons \\
\hline
\end{tabular}

\section{Boiler Plant Metrics}

\begin{tabular}{|l|c|}
\hline Description & Units \\
\hline Hot Water Pumping Efficiency & kW/MBtu \\
\hline
\end{tabular}

\section{Boiler Plant}

\begin{tabular}{|l|c|}
\hline Parameter & Units \\
\hline Hot Water Supply Temperature & Deg F \\
\hline Hot Water Return Temperature & Deg F \\
\hline Hot Water Pumping Power & $\mathrm{kW}$ \\
\hline Hot Water Flow & $\mathrm{gpm}$ \\
\hline Boiler Gas Input & $\mathrm{ft}^{3} \mathrm{H}$ \\
\hline Boiler Efficiency & $\%$ \\
\hline Total Gas Use & Therms \\
\hline
\end{tabular}

\section{Other Metrics}

\begin{tabular}{|l|c|}
\hline Description & Units \\
\hline DI Plant Efficiency & $\mathrm{kW} / \mathrm{gpm}$ \\
\hline Nitrogen Plant Efficiency & $\mathrm{cfm} / \mathrm{kW}$ \\
\hline House Vacuum Efficiency & $\mathrm{cfm} / \mathrm{kW}$ \\
\hline Hot Water Pumping Efficiency & $\mathrm{kW} / \mathrm{MBtu}$ \\
\hline Compressed Air & $\mathrm{BHP} / 100 \mathrm{acfm}$ \\
\hline Lighting & $\mathrm{W} / \mathrm{ft}^{2}$ \\
\hline
\end{tabular}


Process Utilities

\begin{tabular}{|l|c|}
\hline Parameter & Units \\
\hline Compressed Air Input & $\mathrm{kW}$ \\
\hline Compressor Air Discharge Pressure & $\mathrm{acfm}$ \\
\hline Nitrogen Plant Input & $\mathrm{kW}$ \\
\hline Nitrogen Plant Output & $\mathrm{cfm}$ \\
\hline DI Water Plant Power & $\mathrm{kW}$ \\
\hline DI Water Output usage & $\mathrm{gpm}$ \\
\hline DI Water Recirculation Rate & $\mathrm{gpm}$ \\
\hline Vacuum Input & $\mathrm{kW}$ \\
\hline Vacuum Output & $\mathrm{cfm}$ \\
\hline Vacuum Output Pressure & $\mathrm{psi}$ \\
\hline
\end{tabular}




\section{Cleanroom Program Checklist for Energy Efficiency Considerations}

The following checklist, although not all-inclusive, can be used to focus the programming team discussions to many of the areas having a large impact on energy use in cleanrooms.

\begin{tabular}{|c|c|}
\hline Topic & Consideration \\
\hline \multicolumn{2}{|l|}{ Process Heat Load } \\
\hline & Use of name plate data \\
\hline \multicolumn{2}{|r|}{ Load diversification } \\
\hline \multicolumn{2}{|r|}{ Process to develop load and conservatism } \\
\hline \multicolumn{2}{|r|}{ Provision for efficient part load operation and expansion } \\
\hline \multicolumn{2}{|l|}{ Contamination Control } \\
\hline \multicolumn{2}{|r|}{ Cleanliness classification } \\
\hline \multicolumn{2}{|r|}{ Recirculation air change/velocity targets } \\
\hline \multicolumn{2}{|r|}{ Filter coverage } \\
\hline \multicolumn{2}{|r|}{ Filter efficiency } \\
\hline \multicolumn{2}{|r|}{ Make-up/exhaust requirements } \\
\hline \multicolumn{2}{|l|}{$\begin{array}{l}\text { Recirculation air } \\
\text { Systems }\end{array}$} \\
\hline \multicolumn{2}{|r|}{ Efficiency target } \\
\hline \multicolumn{2}{|r|}{ Air management scheme } \\
\hline \multicolumn{2}{|r|}{ Air change/velocity targets } \\
\hline \multicolumn{2}{|r|}{ Controls for flow reduction } \\
\hline \multicolumn{2}{|r|}{ Filter media } \\
\hline \multicolumn{2}{|r|}{ Low pressure drop air handlers/system } \\
\hline \multicolumn{2}{|r|}{ Humidification control } \\
\hline \multicolumn{2}{|l|}{$\begin{array}{l}\text { Make-up and } \\
\text { Exhaust Systems }\end{array}$} \\
\hline \multicolumn{2}{|r|}{ Meet code requirements } \\
\hline \multicolumn{2}{|r|}{ Right-size exhaust - process diversification } \\
\hline \multicolumn{2}{|r|}{ Use of heat exhaust } \\
\hline \multicolumn{2}{|r|}{ Efficiency target } \\
\hline \multicolumn{2}{|r|}{ Low pressure drop air handler/system } \\
\hline & Adjacency of fans to cleanroom \\
\hline
\end{tabular}




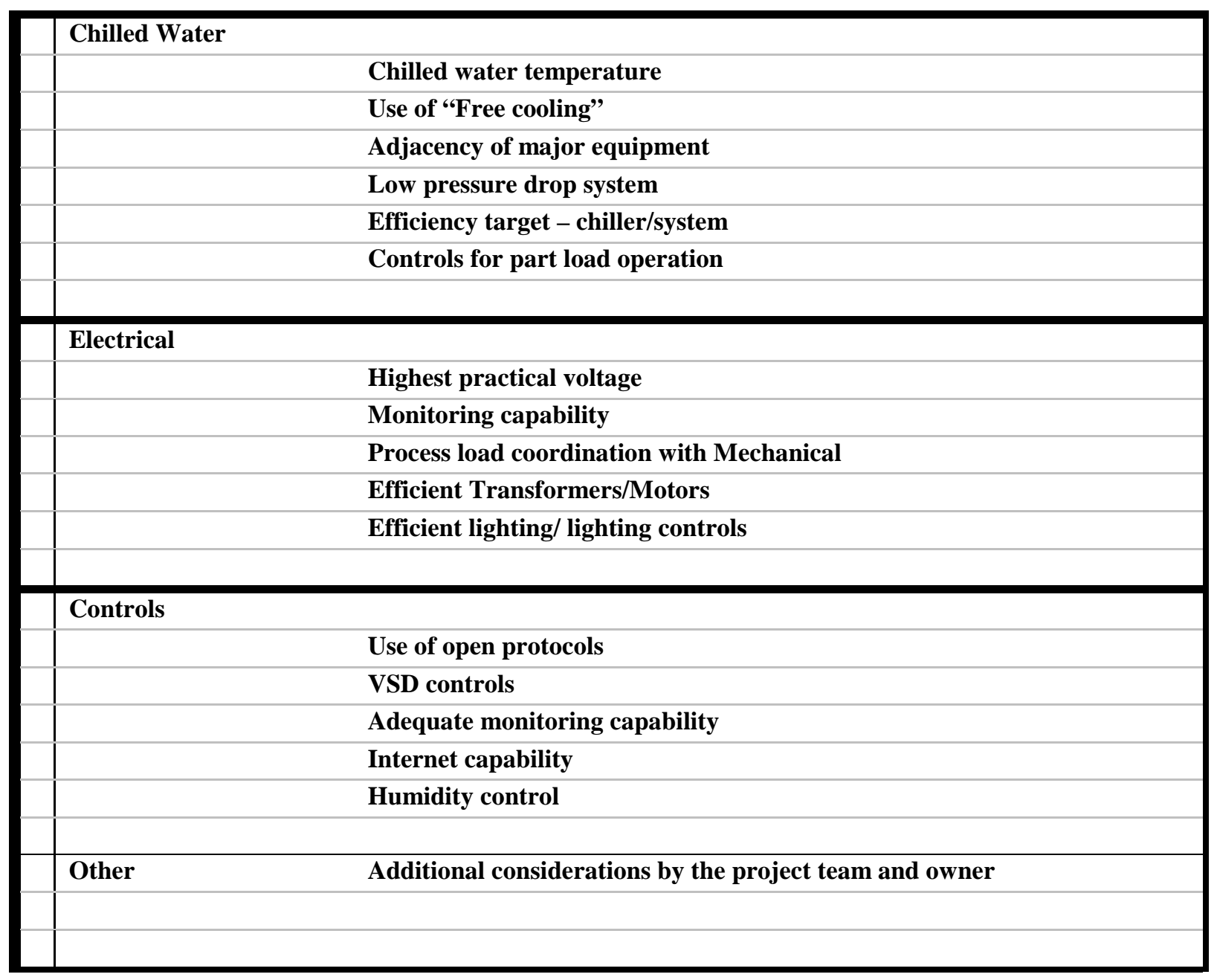

